\title{
Analisa Kepuasan Penumpang Angkutan Kota terhadap Sistem Pelayanan Angkutan Kota di Kota Sidoarjo
}

\author{
Ibnu Sholichin \\ Staff Pengajar Jurusan Teknik Sipil FTSP UPN Veteran Jatim \\ Email: ibnu_sholichin@yahoo.com
}

\begin{abstract}
ABSTRAK
Sistem pelayanan angkutan kota di Sidoarjo memegang peranan yang sangat penting. Sistem pelayanannya saat ini mengikuti sistem jaringan trayek. Walaupun sistem pelayanan angkutan kota sudah mengikuti sistem jaringan trayek, pelayanan dari trayek-trayek yang ada dirasakan kurang, misalnya dalam hal waktu tunggu, ketersediaan kendaraan, kenyamanan dan banyak lagi. Oleh sebab itu, perlu dilakukan penelitian mengenai seberapa besar kepuasan dan harapan penumpang angkot di Kota Sidoarjo terhadap kinerja angkot di Kota Sidoarjo saat ini. Penelitian ini dilakukan dengan menyebarkan kuisioner pada penumpang angkot di Kota Sidoarjo dan Pemerintah Kota Sidoarjo. Kuisioner ini berisi beberapa pertanyaan yang digunakan untuk mengukur tingkat kepuasan dan kepentingan bagi penumpang angkot dan pegawai Pemerintah Kota Sidoarjo terhadap sistem yang berlaku saat ini, yaitu: kapasitas, aksesibilitas, keandalan, tarif terjangkau, frekuensi, responsiveness, tangible, dan jumlah angkot. Pada penelitian ini akan digunakan metode deskriptif-kuantitatif. Tingkat kepuasan penumpang angkot dan Pemerintah Kota Sidoarjo dianalisis dengan menggunakan analisis tingkat kepentingan dan kinerja/kepuasan pelanggan (analisis kuadran). Dari hasil penelitian, menunjukkan bahwa kinerja angkot di kota Sidoarjo yang berkenaan dengan pelayanan angkot berada dalam kuadran C dan $D$. Selain itu, terdapat pula beberapa atribut yang pelaksanaannya dapat dipertahankan yaitu faktor muat, ketetapan jadwal waktu dalam menunggu angkot, dan pelayanan angkot dengan frekuensi yang tinggi. Ketiga atribut tersebut berada dalam kuadran B. Hal ini di tunjukkan pada diagram kartesius.
\end{abstract}

Kata Kunci: Angkutan Kota, Sidoarjo, Analisa Kuadran, Kinerja, Kepuasan

\section{PENDAHULUAN}

Kota Sidoarjo adalah kota terbesar kedua setelah Surabaya di Propinsi Jawa Timur untuk itu sistem transportasi khususnya angkutan kota memegang peranan yang sangat penting. Sistem pelayanan angkutan kota di Sidoarjo saat ini mengikuti sistem jaringan trayek. Sistem pelayanan angkot yang mengikuti jaringan trayek memiliki beberapa keunggulan. Keunggulan tersebut antara lain jaminan waktu tempuh yang dapat diperkirakan oleh penumpang angkot saat melakukan perjalanan ke tujuannya, jaminan untuk sampai ke tujuan perjalanan tanpa ada keraguan akan mengalami kejadian diturunkan oleh pengemudi angkot, dan penumpang angkot juga dapat menerima pelayanan angkot pada jalur yang tetap. Selain beberapa keunggulan di atas, sistem pelayanan angkot yang mengikuti jaringan trayek dapat memberikan pelayanan yang tepat. Dimana penumpang angkot sudah mengenal angkot yang dapat ditumpangi untuk mencapai tujuannya. Hal ini sangat memudahkan penumpang angkot dalam melakukan perjalanannya.

Selain situasi ideal di atas, terdapat pula situasi yang kurang menyenangkan yang terkadang dialami oleh para penumpang angkot antara lain waktu tempuh perjalanan tidak dapat diperkirakan. Keadaan ini menimbulkan ketidakpastian waktu yang harus ditempuh oleh penumpang angkot dalam perjalanannya. Harapan tepat waktu untuk sampai pada tujuan tidak dapat dipenuhi, sehingga menimbulkan rasa tidak puas (kecewa). Selain hal tersebut, penumpang angkot terkadang mengalami kejadian diturunkan tidak pada tujuan perjalanannya. Keadaan ini akan terjadi, apabila si pengemudi angkot memperoleh penumpang dengan jumlah yang sedikit sehingga penumpang dialihkan ke angkot lain dengan tujuan yang sama. 
Berdasarkan situasi di atas, kepuasan/ketidakpuasan penumpang angkot terhadap kinerja angkot dengan sistem jaringan trayek perlu mendapatkan perhatian khusus. Hal ini dimaksudkan agar Pemerintah Kota Sidoarjo dapat mengambil kebijakan dalam menerapkan sistem pelayanan angkot di Kota Sidoarjo. Pengambilan kebijakan tersebut harus diupayakan berdasarkan tingkat kepuasan penumpang angkot yaitu antara harapan dan kinerja angkot.

\section{TINJ AUAN PUSTAKA}

\section{Teori Kepuasan Konsumen}

Untuk mengukur tingkat keberhasilan atau kinerja dari sistem transportasi ada beberapa parameter yang dapat dilihat, yaitu: menyangkut ukuran kuantitatif yang dinyatakan dengan pelayanan, dan yang bersifat kualitatif yang dinyatakan dengan mutu pelayanan (Nasution, 2004) [1]. Kepuasan konsumen banyak ditentukan oleh kualitas performa pelayanan di lapangan (Yoeti, 2005) [2]. Bila pelayanan tidak sesuai dengan harapan konsumen, maka di mata konsumen pelayanan yang diberikan dinilai jelek.

Satisfaction $=f$ [Performance - Expectation $]$

Persamaan ini menghasilkan tiga kemungkinan, yaitu:

Pertama : Performance < Expectation

Bila ini terjadi, maka konsumen mengatakan bahwa pelayanan yang diberikan jelek, karena harapan konsumen tidak terpenuhi sehingga belum memuaskan konsumen.

Kedua : Performance $=$ Expectation

Bila keadaan ini terjadi, maka bagi konsumen pelayanan yang diberikan biasa-biasa saja, karena belum memuaskan konsumen.

Ketiga : Performance $>$ Expectation

Bila keadaan ini tercapai, maka konsumen mengatakan pelayanan yang diberikan adalah baik dan menyenangkan.

\section{Metode Pengukuran Kepuasan Konsumen}

Untuk mengukur tingkat kepuasan penumpang angkot dan pegawai Pemerintah Kota Sidoarjo terhadap sistem pelayanan angkot yang tidak mengikuti jaringan trayek, maka digunakan metode "Analisis Kuadran". Jasa akan menjadi sesuatu yang sangat bermanfaat apabila didasarkan pada kepentingan pelanggan dan kinerjanya bagi perusahaan. Menurut (Supranto, 2006) dalam hal ini [3], digunakan skala 5 tingkat (Likert) yang terdiri dari sangat penting, penting, cukup penting, kurang penting dan tidak penting. Kelima penilaian tersebut, diberikan bobot sebagai berikut:

a. Jawaban sangat penting diberi bobot 5

b. Jawaban penting diberi bobot 4

c. Jawaban cukup penting diberi bobot 3

d. Jawaban kurang penting diberi bobot 2

e. Jawaban tidak penting diberi bobot 1

Tingkat kesesuaian adalah hasil perbandingan skor kinerja/pelaksanaan dengan skor kepentingan. Dalam penelitian ini terdapat 2 buah variabel yang diwakilkan oleh huruf $X$ dan $Y$. Di mana, $X$ merupakan tingkat kinerja angkot yang dapat memberikan kepuasan para pelanggan, sedangkan Y merupakan tingkat kepentingan pelanggan. Adapun rumus-rumus yang digunakan adalah:

$\mathrm{Tk}_{\mathrm{i}}=\frac{\mathrm{X}_{\mathrm{i}}}{\mathrm{Y}_{\mathrm{i}}} \times 100 \%$

Dimana:

Tki = Tingkat kesesuaian responden.

$\mathrm{Xi}=$ Skor penilaian kinerja angkot.

$\mathrm{Yi}_{i}=$ Skor penilaian kepentingan pelanggan (penumpang angkot dan pegawai Pemerintah Kota Sidoarjo).

Selanjutnya sumbu mendatar $(\mathrm{X})$ akan diisi oleh skor tingkat pelaksanaan, sedangkan sumbu tegak ( $Y$ ) akan diisi oleh skor tingkat kepentingan. Dengan penyederhanaan rumus, didapatkan:

$$
\begin{aligned}
& \bar{X}=\frac{\sum X_{i}}{n} \\
& \bar{Y}=\frac{\sum Y_{i}}{n}
\end{aligned}
$$


Di mana:

$$
\begin{aligned}
\overline{\mathrm{X}}= & \begin{array}{l}
\text { Skor rata-rata tingkat pelaksanaan } / \\
\text { kepuasan. }
\end{array} \\
\overline{\mathrm{Y}}= & \text { Skor rata-rata tingkat kepentingan. } \\
\mathrm{n}= & \text { Jumlah responden }
\end{aligned}
$$

Diagram kartesius merupakan suatu bangun yang dibagi atas empat bagian yang dibatasi oleh dua garis yang berpotongan tegak lurus pada titik-titik $(\overline{\bar{X}}, \overline{\bar{Y}})$, di mana $\overline{\bar{X}}$ merupakan rata-rata dari rata-rata skor tingkat pelaksanaan atau kepuasan penumpang angkot seluruh faktor atau atribut. $\overline{\bar{Y}}$ adalah rata-rata dari rata-rata skor tingkat kepentingan seluruh faktor yang mempengaruhi kepuasan penumpang angkot. Rumus selanjutnya sebagai berikut:

$$
\begin{aligned}
& \overline{\bar{X}}=\frac{\sum{ }_{i}^{N}=1 \bar{X} i}{K} \\
& \overline{\bar{Y}}=\frac{\sum{ }_{i}^{N}=1 \bar{Y} i}{K}
\end{aligned}
$$

Di mana:

$$
\begin{aligned}
\mathrm{K}= & \text { Banyaknya atribut/fakta yang dapat } \\
& \text { mempengaruhi kepuasan pelanggan }
\end{aligned}
$$

Selanjutnya tingkat unsur-unsur tersebut akan dijabarkan dan menjadi empat bagian ke dalam diagram kartesius seperti pada gambar 1.

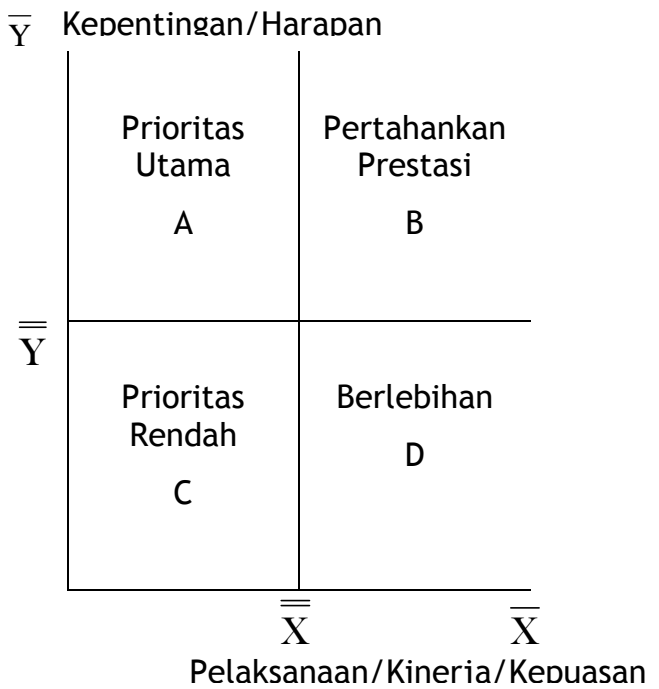

\section{Gambar 1. Diagram Kartesius (Supranto, 2006) [3]}

Keterangan:

A. Menunjukkan faktor atau atribut yang dianggap mempengaruhi kepuasan pelanggan, termasuk unsur-unsur jasa yang dianggap sangat penting, namun manajemen belum melaksanakannya sesuai keinginan pelanggan, sehingga mengecewakan/tidak puas, (prioritas utama).

B. Menunjukkan unsur jasa pokok yang telah berhasil dilaksanakan, untuk itu wajib dipertahankannya. Dianggap sangat penting dan sangat memuaskan, (pertahankan prestasi).

C. Menunjukkan beberapa faktor yang kurang penting pengaruhnya bagi pelanggan, pelaksanaannya biasa-biasa saja. Dianggap kurang penting dan kurang memuaskan, (prioritas rendah).

D. Menunjukkan faktor yang mempengaruhi pelanggan kurang penting, akan tetapi pelaksanaannya berlebihan. Dianggap kurang penting tetapi sangat memuaskan, (berlebihan).

\section{METODE PENELITIAN}

Adapun langkah-langkah penelitian yang dilakukan sebagai berikut:

1. Langkah pertama adalah melakukan melakukan survai pendahuluan. Dalam tahap ini juga dilakukan pembagian zona. Pembagian zona didasarkan atas wilayah kecamatan yang akan dilalui angkot. Dalam penelitian ini ditentukan 6 rute trayek, meliputi:
a. Lyn HP : Terminal Larangan - Sedati Agung.
b. Lyn HBI : Terminal Larangan - Pasar Tulangan.
c. Lyn HB2 : Terminal Larangan - Prambon
d. Lyn HMI : Terminal Larangan - Sudimro Medalem

e. Lyn LS : Terminal Larangan - Sidodadi f. Lyn HD : Terminal Larangan - Candi

2. Langkah kedua adalah penyebaran uji coba kuisioner pada 30 responden penumpang angkot untuk mengetahui tingkat kesulitan pengisian kuisioner.

3. Langkah ketiga adalah pengumpulan data pimer, berupa: penyebaran 
kuisioner bagi penumpang angkot dan pegawai Pemerintah Kota Sidoarjo untuk masing-masing rute trayek sebanyak 30 responden.

4. Langkah keempat adalah analisa data dengan menggunakan analisa kuadran.

5. Langkah kelima adalah mengevaluasi hasil analisis yang didapatkan.

6. Langkah keenam adalah memberikan kesimpulan dan opini guna memberikan solusi kepada Pemerintah Kota Sidoarjo. Hasil penelitian ini diharapkan dapat memudahkan Pemerintah Kota Sidoarjo dalam pengambilan kebijakan guna memperbaiki kinerja dan sistem pelayanan angkot di Kota Sidoarjo.

Uji Kuisioner Meliputi Validitas dan Reliabilitas

Validitas

Suatu tes atau instrumen pengukur dapat dikatakan mempunyai validitas yang tinggi apabila alat tersebut menjalankan fungsi ukurnya, atau memberikan hasil ukur, yang sesuai dengan maksud dilakukannya pengukuran tersebut (Azwar, 2006) [4]. Untuk mengetahui valid tidaknya pertanyaan pada suatu kuisioner maka digunakan persamaan r. Hal ini disebabkan nilai koefisien korelasi sebenarnya tidak sering diketahui, yang kemudian diperkirakan dengan r. Koefisien korelasi sederhana ditunjukkan dengan simbol $\rho$ dan $r$ sebagai perkiraan (Supranto, 2006) [3].

$\mathrm{r}=\frac{\mathrm{n} \sum \mathrm{X}_{\mathrm{i}} \mathrm{Y}_{\mathrm{i}}-\sum \mathrm{X}_{\mathrm{i}} \sum \mathrm{Y}_{\mathrm{i}}}{\sqrt{\left[\mathrm{n} \sum \mathrm{X}_{\mathrm{i}}{ }^{2}-\left(\sum \mathrm{X}_{\mathrm{i}}\right)^{2}\right] \sqrt{\left[\mathrm{n} \sum \mathrm{Y}_{\mathrm{i}}{ }^{2}-\left(\sum \mathrm{Y}_{\mathrm{i}}\right)^{2}\right]}}}$

Di mana:

$r=$ Koefisien korelasi

$\mathrm{Xi}=$ Skor item (satu pertanyaan)

$\mathrm{Yi}=$ Skor total (seluruh item/seluruh pertanyaan)

$\mathrm{n}=$ Jumlah Sampel

Koefisien korelasi ( $r$ ) adalah statistik yang menunjukkan kuat dan arah saling hubungan antara variasi dua distribusi skor (Azwar, 2006) [4]. Setelah diperoleh harga $r$ hitung, selanjutnya untuk dapat diputuskan instrumen tersebut valid atau tidak, harga tersebut dikonsultasikan dengan harga $r$ tabel (Sugiyono, 2006) [5]. Jika harga $r$ hitung lebih besar dari harga $r$ tabel, maka dapat disimpulkan intrumen pada kuisioner tersebut valid atau dapat dipergunakan untuk penelitian.

\section{Reliabilitas}

Menurut (Supranto, 2006) [3], reliabilitas (keandalan) didefinisikan sebagai seberapa jauh pengukuran bebas dari varian kesalahan acak (free from random-error variance). Kesalahan acak menurunkan tingkat keandalan hasil pengukuran. Untuk menguji reliabilitas digunakan teknik Alfa Cronbach. Rumus koefisien reliabilitas Alfa Cronbach (Sugiyono, 2006) [5]:

$$
\mathrm{r}_{\mathrm{i}}=\frac{\mathrm{k}}{(\mathrm{k}-1)}\left\{1-\frac{\sum \mathrm{S}_{\mathrm{i}}^{2}}{\mathrm{St}^{2}}\right\}
$$

\section{Di mana:}

$$
\begin{array}{ll}
\mathrm{ri} & =\begin{array}{l}
\text { Koefisien reliabilitas Alfa } \\
\text { Cronbach }
\end{array} \\
\mathrm{k} & =\text { Jumlah item dalam instrumen } \\
\mathrm{SSi}^{2} & =\text { Varians item } \\
\mathrm{St}^{2} & =\text { Varians total }
\end{array}
$$

Rumus untuk varians total dan varians item (Sugiyono, 2006) [5]:

$$
\begin{aligned}
& \mathrm{St}^{2}=\frac{\sum \mathrm{X}_{\mathrm{t}}{ }^{2}}{\mathrm{n}}-\frac{\left(\sum \mathrm{X}_{\mathrm{t}}\right)^{2}}{\mathrm{n}^{2}} \\
& \mathrm{Si}^{2}=\frac{\mathrm{JKi}}{\mathrm{n}}-\frac{\mathrm{JKs}}{\mathrm{n}^{2}} \ldots . . . . . . . . .
\end{aligned}
$$

Di mana:

$$
\begin{aligned}
\mathrm{Xt} & =\text { Skor pertanyaan ke } \mathrm{t} \\
\mathrm{Jki} & =\text { Jumlah kuadrat seluruh skor item } \\
\mathrm{Jks} & =\text { Jumlah kuadrat subjek } \\
\mathrm{n} & =\text { Jumlah sampel }
\end{aligned}
$$

Secara empirik, tinggi rendahnya reliabilitas ditunjukkan oleh suatu angka yang disebut koefisien reliabilitas. Tinggi rendahnya reliabilitas tes dicerminkan oleh koefisien korelasi antara skor pada dua tes yang paralel, yang dikenakan pada sekelompok individu yang sama. Semakin tinggi koefisien korelasi termaksud berarti konsistensi antara hasil pengenaan dua tes tersebut semakin baik dan hasil ukur kedua tes itu 
dikatakan semakin reliabel. Sebaliknya, apabila dua tes yang dianggap paralel ternyata menghasilkan skor yang satu sama lain berkorelasi rendah, maka dapat dikatakan bahwa reliabilitas hasil ukur tersebut tidak tinggi (Azwar, 2006) [3].

\section{HASIL DAN PEMBAHASAN}

Hasil perhitungan tingkat kesesuaian skor kinerja angkot dengan skor kepentingan pelayanan angkot di Kota Sidoarjo dapat di lihat pada tabel 1

Tabel 1. Nilai Tingkat Kesesuaian Kinerja Angkot Bagi Penumpang Angkot

\begin{tabular}{|c|c|c|c|}
\hline Atribut & $\begin{array}{c}\text { Kepuasan/ } \\
\text { Kinerja }\end{array}$ & $\begin{array}{c}\text { Kepentingan/ } \\
\text { Harapan }\end{array}$ & $\begin{array}{c}\text { Tingkat } \\
\text { Kesesuaian } \\
(\%)\end{array}$ \\
\hline 1 & 572,00 & 832,00 & 68,75 \\
\hline 2 & 303,00 & 235,00 & 128,94 \\
\hline 3 & 262,00 & 237,00 & 110,55 \\
\hline 4 & 331,00 & 261,00 & 126,82 \\
\hline 5 & 525,00 & 824,00 & 63,71 \\
\hline 6 & 439,00 & 271,00 & 161,01 \\
\hline 7 & 278,00 & 227,00 & 122,47 \\
\hline 8 & 292,00 & 229,00 & 123,51 \\
\hline 9 & 611,00 & 784,00 & 77,93 \\
\hline 10 & 279,00 & 251,00 & 111,16 \\
\hline $\begin{array}{c}\text { Rata- } \\
\text { rata }\end{array}$ & 389,20 & 415,10 & 100,00 \\
\hline
\end{tabular}

Sumber: Data Primer

Pada tabel 1, diperoleh tingkat kesesuaian hasil perbandingan antara skor kinerja/kepuasan dengan skor kepentingan/harapan. Dari tabel di atas dapat disimpulkan urutan prioritas peningkatan faktor-faktor yang mempengaruhi kepuasan penumpang angkot. Urutan prioritas peningkatan faktorfaktor kepuasan penumpang angkot dapat diurutkan sebagai berikut:

1. Faktor ketetapan jadwal waktu dalam menunggu angkot sebesar 63,71\% (item 5)

2. Faktor muat sebesar $68,75 \%$ (item 1)

3. Faktor pelayanan angkot dengan frekuensi yang tinggi sebesar 77,93\% (item 9)

4. Faktor waktu yang terbuang sia-sia akibat diturunkan oleh pengemudi angkot sebesar 110,55\% (item 3)
5. Faktor jalur angkot di Kota Sidoarjo yang tidak mengikuti rute sebesar $111,16 \%$ (item 10)

6. Faktor di turunkan pengemudi angkot, tidak pada tujuan perjalanan sebesar $122,47 \%$ (item 7 )

7. Faktor jarak perjalanan yang tidak mengikuti rute sebesar 126,82\% (item 4)

8. Faktor biaya angkot yang tidak mengikuti rute, ditambah lagi biaya angkot jika di turunkan pengemudi angkot sebesar 123,51\% (item 8)

9. Faktor waktu perjalanan yang tidak mengikuti rute sebesar $128,94 \%$ (item 2)

10. Faktor adanya waktu tunggu, akibat di turunkan pengemudi angkot untuk mendapatkan angkot berikutnya sebesar $161,01 \%$ (item 6)

Dari urutan prioritas di atas dapat di lihat bahwa faktor yang paling tidak sesuai antara harapan dan kepuasan adalah faktor adanya waktu tunggu, akibat di turunkan pengemudi angkot untuk mendapatkan angkot berikutnya. Sedangkan hasil perhitungan faktor-faktor kepuasan penumpang angkot dapat di lihat pada tabel 2.

Tabel 2.Faktor-Faktor Kepuasan Penumpang Angkot Di Sidoarjo

\begin{tabular}{|c|c|c|c|c|}
\hline \multirow[t]{2}{*}{$\begin{array}{c}\text { Atri- } \\
\text { but }\end{array}$} & $\begin{array}{c}\text { Kepuas- } \\
\text { an/ } \\
\text { Kinerja }\end{array}$ & $\begin{array}{l}\text { Kepen- } \\
\text { tingan/ } \\
\text { Harapan }\end{array}$ & \multirow{2}{*}{$\begin{array}{c}\text { Tingkat } \\
\text { Kesesuaian } \\
\text { (\%) }\end{array}$} & \multirow[t]{2}{*}{ Selisih } \\
\hline & $\overline{\mathrm{X}}$ & $\bar{Y}$ & & \\
\hline 1 & 2,86 & 4,16 & 68,75 & $-1,30$ \\
\hline 2 & 1,52 & 1,18 & 128,94 & 0,34 \\
\hline 3 & 1,31 & 1,19 & 110,55 & 0,13 \\
\hline 4 & 1,66 & 1,31 & 126,82 & 0,35 \\
\hline 5 & 2,63 & 4,12 & 63,71 & $-1,50$ \\
\hline 6 & 2,20 & 1,36 & 161,01 & 0,84 \\
\hline 7 & 1,39 & 1,14 & 122,47 & 0,26 \\
\hline 8 & 1,46 & 1,15 & 123,51 & 0,32 \\
\hline 9 & 3,06 & 3,92 & 77,93 & $-0,87$ \\
\hline 10 & 1,40 & 1,26 & 111,16 & 0,14 \\
\hline $\begin{array}{c}\text { Rata- } \\
\text { rata }\end{array}$ & 1,95 & 2,08 & 100,00 & $-0,13$ \\
\hline
\end{tabular}

Sumber: Data Primer 
Dari tabel 2 dapat di lihat, untuk rata-rata dari rata-rata skor tingkat kepuasan penumpang angkot seluruh faktor $(\overline{\bar{X}})$ diperoleh nilai sebesar 1,95. Sementara untuk rata-rata dari rata-rata skor tingkat kepentingan seluruh faktor yang mempengaruhi kepuasan penumpang angkot $(\overline{\overline{\mathrm{Y}}})$ sebesar 2,08.
Sedangkan pada gambar 2 di perlihatkan faktor-faktor kepuasan penumpang angkot yang terletak pada diagram kartesius. Diagram ini memiliki besaran skala yang sama antara sumbu mendatar dan sumbu tegak (rentang nilai 0-5). Pada diagram tersebut diperlihatkan letak atau posisi nilai-nilai kepuasan penumpang angkot yang dibandingkan dengan sumbu diagonal.

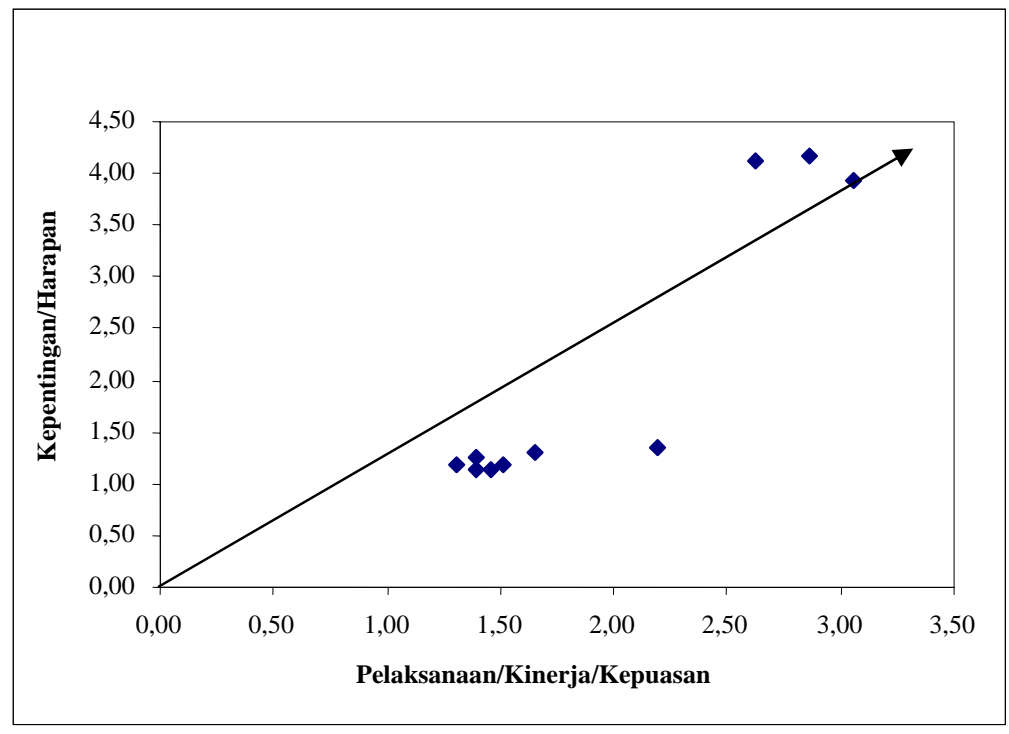

\section{Gambar 2. Nilai Faktor-Faktor Kepuasan Penumpang Angkot Dan Letaknya Pada Diagram Kartesius}

Dari gambar di atas, menunjukkan penyebaran titik-titik yang terletak pada diagram kartesius. Posisi penyebaran titiktitik tersebut dibandingkan dengan sumbu diagonal. Sementara pada diagram kartesius mempertegas posisi faktor-faktor yang mempengaruhi kepuasan penumpang angkot terhadap kinerja angkot. Hal ini dipertegas pada keempat kuadran yang dibatasi oleh sumbu mendatar $(\overline{\mathrm{X}})$ dan sumbu tegak ( $\overline{\mathrm{Y}}$ ) yang saling berpotongan dititik $(\overline{\bar{X}}, \overline{\bar{Y}})$. 


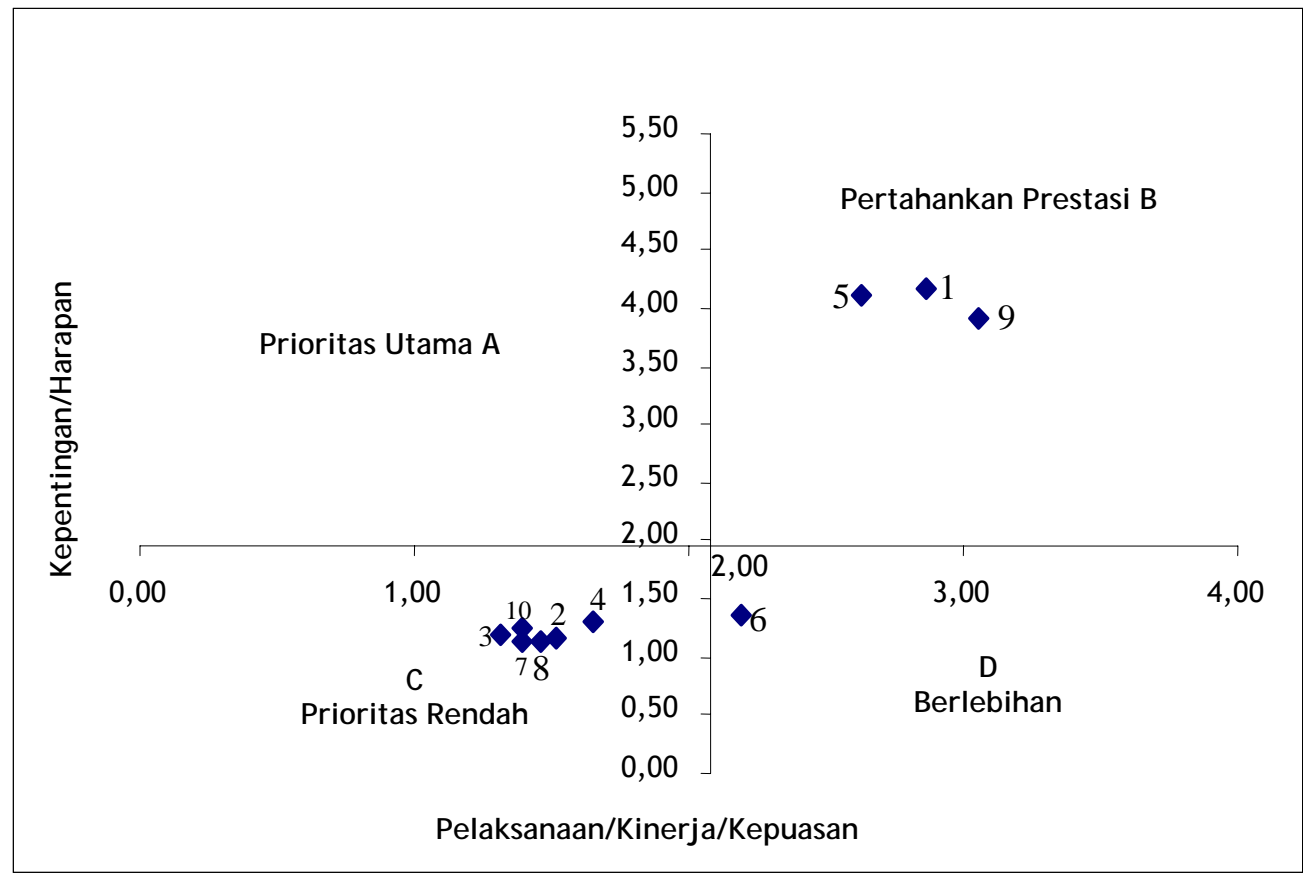

Gambar 3. Diagram Kartesius Dari Faktor-Faktor Yang Mempengaruhi Kepuasan Penumpang Angkot Terhadap Pelayanan Kinerja Angkot Di Kota Sidoarjo

Keterangan:

1. Faktor Muat

2. Faktor waktu perjalanan yang tidak mengikuti rute

3. Faktor waktu yang terbuang sia-sia akibat diturunkan oleh pengemudi angkot

4. Faktor jarak perjalanan yang tidak mengikuti rute

5. Faktor ketetapan jadwal waktu dalam menunggu angkot

6. Faktor adanya waktu tunggu, akibat di turunkan pengemudi angkot untuk mendapatkan angkot berikutnya

7. Faktor di turunkan pengemudi angkot, tidak pada tujuan perjalanan

8. Faktor biaya angkot yang tidak mengikuti rute, ditambah lagi biaya angkot jika di turunkan pengemudi angkot

9. Faktor pelayanan angkot dengan frekuensi yang tinggi

10. Faktor jalur angkot di Kota Sidoarjo yang tidak mengikuti rute

Pada gambar 3, diperlihatkan letak faktorfaktor kepuasan penumpang angkot terhadap kepentingan penumpang angkot. Faktorfaktor tersebut berada pada tiga kuadran yaitu pertahankan prestasi (kuadran B), prioritas rendah (kuadran $\mathrm{C}$ ), dan berlebihan (kuadran D).

\section{KESIMPULAN}

Berdasarkan hasil dan pembahasan dapat ditarik kesimpulan sebagai berikut:

a. Berdasarkan jawaban responden (penumpang angkot) dari hasil analisis kuadran (dengan tingkat kesesuaian), maka diperoleh kesimpulan sebagai berikut:

1. Kuadran B, faktor-faktor yang perlu dipertahankan pelaksanaan dan keberadaannya karena sudah sesuai dengan harapan penumpang angkot yaitu:

a. Faktor ketetapan jadwal waktu dalam menunggu angkot sebesar $63,71 \%$.

b. Faktor muat sebesar $68,75 \%$. 
c. Faktor pelayanan angkot dengan frekuensi yang tinggi sebesar $77,93 \%$.

Variabel-variabel pada kuadran ini merupakan faktor-faktor yang paling berpengaruh terhadap kinerja angkot berdasarkan kepuasan penumpang angkot. Hal ini terlihat, para responden memberikan nilai kepentingan yang tinggi dan nilai kinerja yang dirasakan sama dengan harapan.

2. Kuadran C, faktor-faktor yang dinilai tidak penting oleh penumpang angkot, dan kinerjanya dinilai kurang baik oleh penumpang angkot yaitu:

a. Faktor waktu yang terbuang siasia akibat diturunkan oleh pengemudi angkot sebesar $110,55 \%$.

b. Faktor jarak perjalanan yang tidak mengikuti rute sebesar $126,82 \%$.

c. Faktor biaya angkot yang tidak mengikuti rute, ditambah lagi biaya angkot jika di turunkan pengemudi angkot sebesar $123,51 \%$.

d. Faktor waktu perjalanan yang tidak mengikuti rute sebesar $128,94 \%$.

Variabel-variabel pada kuadran ini merupakan faktor-faktor yang tidak berpengaruh terhadap kinerja angkot berdasarkan kepuasan penumpang angkot. Hal ini terlihat para responden memberikan nilai kepentingan yang rendah dan nilai kinerja yang rendah pula terhadap faktor-faktor tersebut.

3. Kuadran D, faktor-faktor yang dinilai tidak penting oleh penumpang angkot, akan tetapi pelaksanaan kinerjanya dinilai lebih baik oleh penumpang angkot yaitu faktor adanya waktu tunggu, akibat di turunkan pengemudi angkot untuk mendapatkan angkot berikutnya sebesar 161,01\%.

b. Terdapat beberapa faktor yang mempengaruhi kepuasan penumpang angkot terhadap kinerja angkot di Kota Sidoarjo. Faktor-faktor tersebut terletak dalam kuadran B pada diagram kartesius. Faktorfaktor yang terdapat dalam kuadran B, yaitu:

1. Ketetapan jadwal waktu dalam menunggu angkot.

2. Kapasitas yang dinyatakan dalam load faktor.

3. Pelayanan angkot dengan frekuensi yang tinggi.

Ketiga faktor di atas merupakan faktorfaktor yang mempengaruhi kinerja angkot di Kota Sidoarjo, berdasarkan penilaian pengguna angkot.

c. Dari uraian diatas, masukan untuk perbaikan kinerja angkot di Sidoarjo adalah memperpendek waktu tunggu angkot sehingga waktu tidak terbuang sia-sia. Hal ini bisa dilakukan dengan mengubah sistem pemberangkatan angkot saat ini yang berupa "totolan" (angkot tidak berangkat kalau tidak ada angkot yang datang) dengan sistem waktu (menit), misal setiap 10 menit angkot berangkat.

\section{DAFTAR PUSTAKA}

Acuan yang digunakan dalam penyusunan penelitian ini adalah sebagai berikut :

[1] Nasution, M.N, (2004), Manaj emen Transportasi, Edisi Kedua, Ghalia Indonesia, Jakarta.

[2] Yoeti, H.O.A, (2005), Customer Service Cara Efektif Memuaskan Pelanggan, Cetakan Keempat, PT Pradnya Paramita, Jakarta.

[3] Supranto, J, (2006), Pengukuran Tingkat Kepuasan Pelanggan Untuk Menaikkan Pangsa Pasar, PT Rineka Cipta, Jakarta.

[4] Azwar, S, (2006), Realibilitas dan Validitas, Cetakan Keenam, Pustaka Pelajar, Jogjakarta.

[5] Sugiyono, (2006), Statistik Untuk Penelitian, Cetakan Kesembilan, CV AlfaBeta, Bandung. 